\title{
La ecúmene de vivos y muertos. Mala muerte y reparaciones territoriales en el Bajo Atrato
}

\author{
The Ecumene of the Living and the Dead. Bad Death \\ and Territorial Reparations in Bajo Atrato
}

\author{
Daniel Ruiz-Serna* \\ University of British Columbia y \\ Center for Oral History and Digital Storytelling, Concordia University, Canadá
}

DOI: $10.22380 / 2539472 X .639$

\section{RESUMEN}

En las selvas del Bajo Atrato, los combates entre guerrillas y paramilitares dejaron decenas de cuerpos sin enterrar que, transformados ahora en espíritus, han alterado las posibilidades que tienen las comunidades locales de habitar y sanar sus territorios colectivos. Sostengo que estos espíritus hacen parte de un conjunto más amplio de experiencias de dolor y sufrimiento que se inscriben en ámbitos que rebasan lo humano. Argumento que dichas experiencias constituyen un tipo de daño territorial y que su comprensión etnográfica es condición para el diseño de estrategias locales de paz y políticas regionales de reconciliación.

Palabras clave: daño, territorio, reconci-

liación, relaciones entre humanos y no-

humanos.

\begin{abstract}
In the forests of the Bajo Atrato region, battles between guerrilla and paramilitary armies left a multitude of unburied corpses whose spirits have transformed the way in which local communities inhabit and heal their collective lands. It is argued that these spirits, along other set of experiences of suffering and pain that extend beyond the human, are a form of territorial damage. Ethnographic attention to this kind of damage is key in order to design adequate local and regional policies of peace and reconciliation.
\end{abstract}

Keywords: damage, territory, reconciliation, human and nonhuman relationships. 


\section{Introducción}

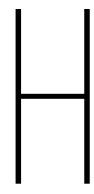

ay presencias que dejan sutiles señales en la selva. Algunas son muy efímeras, como el olor que dejan los saínos al pasar. Otros rastros son perceptibles solo para el ojo adiestrado: huellas en el barro, ramas rotas, rasguños en los árboles. Ciertas presencias dejan trazos que, aunque menos visibles, son registrados por otros sentidos; como cuando alguien camina en la selva y sin motivo aparente siente la carne de gallina y los pelos de punta. En este artículo describo algunas presencias capaces de generar este tipo de reacciones. Se trata de los espíritus de aquellos que sufrieron una mala muerte, esto es, una muerte violenta lejos de la tierra natal y, casi siempre, de la familia. La mala muerte no la define solo la brutal aniquilación del cuerpo sino sobre todo un estado general de abandono y olvido, puesto que los cuerpos de quienes la sufrieron no recibieron los cuidados que se les suele prodigar a través de los rituales funerarios. Por el contrario, en la mayoría de casos, estos cuerpos son dejados en la selva a merced de las aves carroñeras. Mi argumento es que la presencia de estos espíritus no es algo que se relacione exclusivamente con las creencias de ciertas comunidades, es decir, no son solo el resultado de las representaciones culturales que ciertos pueblos se han forjado sobre la muerte. Más bien, dichos espíritus son seres cuya posibilidad de existencia está íntimamente conectada a los lugares en que ocurrieron los hechos violentos. Quiero, pues, discutir cómo participan los lugares de manera esencial y no solo contingente en la generación de sentidos, memorias y sensibilidades. Las experiencias que cultivan algunas comunidades del Bajo Atrato con los lugares que habitan resultan fundamentales en el diseño de estrategias para lograr justicia y sanar sus territorios colectivos ${ }^{1}$.

Este argumento etnográfico se deriva de algunos eventos sucedidos en la desembocadura del Caño Claro en Curvaradó, río localizado en el Bajo Atrato chocoano, región en la que trabajé vinculado a una organización no gubernamental (ONG) de derechos humanos desde el 2003 al 2006, y en la que realicé sucesivos trabajos de campo entre el 2008 y el 2016. El evento al que me refiero sucedió en el 2002, cuando en este caño ocurrió una sangrienta confrontación armada entre los grupos paramilitares del Bloque Élmer Cárdenas de las Autodefensas Unidas de Córdoba y Urabá (ACCU) y el Frente 57 de la guerrilla de las Fuerzas Armadas Revolucionarias de Colombia (FARC). Este fue un evento que

1 Los territorios colectivos son los espacios de vida sobre los que la Ley 70 de 1993 determinó el derecho a la propiedad colectiva por parte de las comunidades negras del Pacífico colombiano. 
no dejó huella en los archivos escritos pero sí todo tipo de vestigios y memorias en el lugar de los hechos: en los relatos de los campesinos que por aquella época retornaron a sus territorios colectivos, así como en las experiencias de quienes hoy transitan y habitan el lugar. Quizá por el hecho de que no hubo víctimas civiles el evento no fue documentado por la prensa de la época. Pero lo sucedido no pasó desapercibido para quienes se toparon con las decenas de cuerpos abaleados que el río arrastró, ni para aquellos que con mucho esfuerzo retornaron a sus tierras en el 2003 para encontrarlas convertidas en cultivos de palma aceitera introducidos por empresarios que realizaron alianzas criminales con los grupos paramilitares locales.

Con este combate como telón de fondo describo los encuentros que las comunidades de Caño Claro tienen con los vestigios dejados por el enfrentamiento: botas, menajes militares, casquillos, fusiles y, por supuesto, osamentas. Enseguida muestro cómo las experiencias con los espíritus que habitan el lugar reflejan una relación más bien ambivalente: por el hecho de haber pertenecido a los grupos armados responsables del desplazamiento y otros crímenes contra las comunidades locales, a los espíritus de estos combatientes aún se les asocia con el daño sufrido; al mismo tiempo, las comunidades plantean acciones para ayudar a que estos espíritus emprendan su viaje al más allá. De este modo se busca sanar el territorio, es decir, permitir que el lugar recobre algunas de sus cualidades materiales y anímicas. Más importante aún, como lo describo en la tercera parte, dichas acciones se inscriben en una ética que considero cosmopolita puesto que trascienden afiliaciones ideológicas y generan condiciones para que el territorio pueda ser habitable tanto por los vivos como por los muertos. Esta sanación y habitabilidad del territorio es a lo que me refiero con ecúmene: el brote o emergencia de un mundo compartido, puesto en marcha a través de una serie de acciones que bien podrían considerarse políticas y que entrelazan a los vivos y a los muertos, pero también a los lugares violentados. Inspirado en el trabajo de Augustin Berque (1987), hago uso del concepto ecúmene para referirme a un proceso dual seguido por las comunidades locales para morar adecuadamente en sus territorios que incluye, por un lado, las prácticas a través de las cuales el territorio se vuelve habitable tanto para humanos como para no humanos; por el otro, la manera en que sus distintos moradores se territorializan, es decir, comparten territorio. Argumento que la interacción entre los mundos parcialmente conectados de los vivos y los muertos constituye una política ecuménica que se asevera indispensable para reparar el territorio y hacer de él un lugar habitable para unos y para otros. 


\section{Un número para ganarse la lotería}

Los ecos de decenas de muertes continúan encapsulados en Caño Claro a pesar de los años transcurridos desde el enfrentamiento entre paramilitares y guerrilleros en el 2002. Quizá sea por la presencia de la selva que reclama su espacio o por el esfuerzo de quienes regresaron a sus tierras a reconstruir sus casas y campos en ruinas que los eventos de aquella confrontación continúan ramificándose en el lugar. Mientras caminaba por allí con Pontus y Esteban ${ }^{2}$ —dos líderes de la cuenca del río Curvaradó-, mis ojos no pudieron distinguir nada fuera de lugar. Todo lo que noté fueron los rastrojos de un campo de maíz, un par de palmas de coco y un barril oxidado entre la maleza. Nos detuvimos cerca de una choza sin techo y allí fue donde Pontus empezó a contarme su versión de los eventos, aunque la manera como empezó me pareció más bien uno de esos titulares que a veces pueblan los periódicos: "Al menos 60 paramilitares debieron morir ese día”. Según él, los que se salvaron lo hicieron porque se arrojaron a las correntosas aguas del río, dejando morrales, equipos y fusiles atrás. Los cuerpos de quienes murieron fueron abandonados y se convirtieron en alimento de aves carroñeras. Otros tantos fueron simplemente arrojados por los guerrilleros a las aguas del Curvaradó. Pontus y Esteban me guiaron al lugar exacto donde los paramilitares del Bloque Élmer Cárdenas habían situado su campamento, justo en la desembocadura del Caño Claro. El sitio era estratégico pues marcaba la frontera entre las tierras que fueron abandonadas por las familias pertenecientes a los consejos comunitarios de la cuenca del Curvaradó y las que les fueron despojadas para la implementación de cultivos industriales de palma aceitera.

He buscado en archivos de prensa y otras fuentes escritas algún registro de los hechos sin obtener resultados. Mi hipótesis es que los enfrentamientos no llamaron la atención pública porque no hubo víctimas civiles, lo que me lleva a preguntarme cuántas otras batallas similares han ocurrido a lo largo y ancho del país sin que de ellas sepamos mayor cosa. Con frecuencia se habla de cuán ignorante es el mundo urbano de la realidad del conflicto armado en el campo colombiano: eventos como los de Caño Claro caerían en una doble invisibilización, pues ni siquiera quienes viven en esta región rural tienen certeza de lo que pasó. Pero es que el 2002 fue un año particularmente difícil en el Bajo Atrato. Según cifras del Observatorio del Programa Presidencial de Derechos Humanos (2003), hasta ese año había reportados al menos 130 homicidios y 19 desapariciones forzadas. 
El combate sucedió durante un periodo de terror caracterizado por los asesinatos selectivos de los líderes de los consejos comunitarios de los ríos Jiguamiandó y Curvaradó, quienes con frecuencia fueron detenidos y torturados durante sus recorridos por el río. Precisamente el campamento paramilitar ejercía el control y disciplinamiento de las comunidades locales: funcionó como un retén donde las embarcaciones eran detenidas, los tripulantes requisados e interrogados y sus provisiones controladas e inventariadas.

Según los relatos de quienes en ese entonces retornaron a sus territorios colectivos, el ataque contra el campamento se trató de una fulminante y bien planeada operación de la guerrilla, que además de emboscar a los paramilitares durante la noche los superó en número, dejándoles pocas oportunidades de reaccionar. Algunos dicen que los muertos fueron más de cien, pero nadie lo sabe con certeza. Lo que sí se sabe es que decenas de cadáveres con uniformes camuflados desfilaron aguas abajo y que muchos otros fueron abandonados a su suerte para, como me lo describieron en varias oportunidades, ser comidos por los goleros o chulos. En el sitio todavía es posible encontrar vestigios del campamento: ollas, munición, fusiles y hasta restos de los equipos de dotación. Poco antes de finalizar nuestro recorrido y justo en el momento en que Esteban y yo embarcábamos, Pontus señaló un objeto enterrado en una pendiente del banco del río. Con sus manos lo desenterró y vimos que se trataba de un trozo de toldillo verde oliva. Toda vez que estos son los implementos más importantes de supervivencia para un combatiente que quiera defenderse de las hordas de zancudos que pueblan las selvas chocoanas y de las enfermedades que transmiten, creí percibir en aquel toldillo abandonado los ecos de una muerte que llega de forma repentina y violenta.

En Caño Claro otro tipo de restos afloran de vez en cuando. Doña Aleyda, una viuda de unos sesenta años que vive cerca del lugar, me contó del hallazgo que desenterró un día mientras buscaba lombrices para pescar. Se trataba de una cédula: "Ese muchacho, recuerdo, llamaba Ovidio. Apellido Monterrosa. El dueño de esa cédula era de Necoclí. Yo me dije: 'Con el número de esa cédula voy a hacerme un chance a ver si me lo gano”". Hay también quienes han encontrado restos humanos. Doña Aleyda recuerda que alguna vez alguien quiso jugarle una broma dejando una calavera en el camino que ella suele transitar. Me dijo que el hallazgo le causó gracia, no susto; y que cuando se encontró al bromista le dio un hueso de una mandíbula que ella se había topado antes: “iOh, negro! Ahí quedó la quijada del que se murió para que se la pongas y quede así, riéndose ¡Y de verdad, el bellaco la cogió!” (entrevista, septiembre del 2016). Pero hay encuentros con estos muertos que son más siniestros que toparse con una calavera sonriente. Hay quienes en las noches han oído lamentos provenientes del lugar. 
Otros sienten repentinas ráfagas de aire frío cuando transitan por allí. Muchos evitan pasar por el sitio puesto que tiene una atmósfera incómoda. Un joven me contó de una amiga suya a la que asustaron en ese lugar. Ella pasaba por allí y encontró un pocillo esmaltado sobre un tronco, como los que hacen parte de los menajes de dotación del ejército. En el instante en que tomó el pocillo, escuchó los pasos de un animal grande corriendo a toda velocidad hacia ella. Asustada empezó a correr y se arrojó al río. No quería soltar el pocillo pero nadar con él en la mano fue tan complicado que terminó por hacerlo. Al otro día ella y el joven que me refirió la historia volvieron al sitio y encontraron el pocillo exactamente en el mismo lugar de donde ella inicialmente lo había tomado.

Este tipo de historias muestran cómo los efectos de esas muertes siguen repercutiendo en la vida de la gente, aun después de logradas las desmovilizaciones oficiales de los paramilitares y las FARC. Más importante, los encuentros con estas presencias fantasmagóricas muestran cómo se han transformado las cualidades mismas del lugar. Con cualidades me refiero no tanto a las historias que la gente adscribe al sitio sino al hecho de que la masacre está incrustada y bien presente allí. Lo está físicamente —restos materiales que aún son localizables - pero también afectivamente, quiero decir, como impresiones sensoriales o atmósferas que están aflorando constantemente en el sitio. Siguiendo una lectura anclada en el nuevo materialismo y en la lógica relacional que algunos antropólogos han hecho de la obra del filósofo Baruch Spinoza (1677), con afectos me refiero al conjunto de impresiones que puede provocar un lugar como Caño Claro en los cuerpos de quienes lo recorren y habitan. En la literatura antropológica, los afectos se distinguen de las emociones puesto que a estas últimas se les suele situar en la esfera subjetiva, correspondiendo con estados anímicos instintivos o respuestas psicológicas preculturales ancladas en "las provincias biológicas de la experiencia humana” (Lutz y White 1986, 405). Y aunque son cada vez más las voces que reivindican las emociones como un campo legítimo de indagación antropológica, puesto que son actos comunicativos situados en contextos históricos y elaborados culturalmente a través de los cuales se transmiten aspectos del pensamiento social (véase por ejemplo Jimeno 2004, 2007), la teoría de los afectos pone énfasis en su carácter intersubjetivo y en su posibilidad de afectar cuerpos (y no solo psiques) humanos y no humanos. Afectos son, pues, las impresiones que producen la materialidad tanto de nuestros cuerpos como del mundo mismo, son afecciones del cuerpo, es decir, fuerzas o intensidades que se producen a través de las relaciones que las personas tejen entre sí y en diálogo con sus respectivos mundos de la vida (lifeworlds) (Pelkmans 2013). Con afectos, como discuto a continuación, es la manera en que intento sobrepasar el debate 
de si los lugares son simplemente construidos, esto es, tabulas rasas en las que los humanos imponemos nuestras propias interpretaciones o si, por el contrario, son dados, es decir, fuerzas objetivas capaces de otorgar sentido a, o al menos modelar, nuestras acciones. Al formular las experiencias de quienes han tenido encuentros siniestros en Caño Claro en términos de afectos, busco llamar la atención sobre la forma en que muchas de nuestras experiencias sensoriales son asaltadas por el mundo exterior (Navaro-Yashin 2009; Stewart 2007). Puesto de otra forma, al conceptualizar las presencias fantasmagóricas que habitan Caño Claro en términos de afectos pretendo, por un lado, no anclarme en la dicotomía de si lo que allí aflora corresponde bien a representaciones culturales que la gente se ha formado o bien a fenómenos objetivamente aprehensibles; por otro lado, busco examinar las impresiones que los lugares provocan en la gente, no solo como el resultado de lo que sus respectivos mundos subjetivos proyectan en el mundo exterior, sino también como un producto emergente, esto es, como un conjunto de propiedades que resultan de la interacción continua entre los lugares y los cuerpos que los habitan. El siguiente ejemplo puede aclarar mi punto.

Tras un enfrentamiento entre la guerrilla y los paramilitares cerca de un caserío localizado en la cuenca del río Salaquí, los paramilitares que sobrevivieron llegaron a la comunidad gritando e insultando a los habitantes, culpándolos de la emboscada sufrida. Pasaron por cada una de las casas y se llevaron a los hombres para que les ayudaran a traer los cuerpos de los combatientes que habían quedado en la selva. Los cuerpos fueron apilados a la sombra de un árbol de mango ubicado en el centro del caserío. Después de aquello el árbol empezó a secarse. Alguien me dijo que en ese lugar ahora asustan y que algunas noches se pueden escuchar pasos y lamentos. Lugares como ese árbol están entonces conectados con la memoria de ciertos eventos y, por ello, pueden inspirar determinadas sensaciones. Pero los lamentos y los pasos que se oyen no son solamente el resultado de las historias que circulan acerca del lugar. Más bien esta clase de incidentes de naturaleza violenta dejan un tipo de exceso, una serie de impresiones que se alojan en el sitio y que devienen, hasta cierto punto, independientes de cualquier intencionalidad humana (como las historias que se cuentan de allí). En consecuencia, uno podría asumir que hay lugares que intrínsecamente pueden transmitir ciertos sentidos, es decir, que tienen la capacidad de afectar y dispensar particulares impresiones sobre la gente.

En su sentido más básico, afecto es un evento, es la capacidad "de afectar y ser afectado” (Stewart 2007, 2). De ahí que tenga la potencia de mover o desatar una respuesta en quien es tocado o afectado (Lara y Domínguez 2013, 115). También puede ser definido como la percepción de una intensidad corporal, es decir, 
la impresión de tener una impresión (Massumi 2002). Los afectos pueden circular a través de diferentes cuerpos, tanto humanos como no humanos (Seyfert 2012), puesto que estos cuerpos son definidos, "no por la envoltura externa de la piel ni por otro límite superficial, sino por su potencial para corresponder o coparticipar en el paso de afectos” (Seigworth y Gregg 2010, 2). Kathleen Stewart (2007) considera los afectos en términos de impulsos como "energías sutiles" (70) o "eventos vivos con cierta capacidad de descarga” (68), mientras que Yael Navaro-Yashin (2009) los describe como atmósferas esparcidas sobre la gente por los lugares y los objetos con los que habitan. Al igual que la fenomenología, la teoría de los afectos descentraliza la mente o la conciencia como "órgano" fundamental para el conocimiento y la experiencia del mundo. De ahí que sean los cuerpos, y no meramente las mentes, los lectores o, mejor aún, los coconstituyentes de los afectos.

Coconstitución o coemergencia son conceptos claves para entender el proceso mediante el cual se generan y transmiten los afectos. Coemergencia significa entender la presencia de los espíritus que sufrieron una mala muerte en Caño Claro como una propiedad que surge de un ensamblaje en el que participan cuerpos (humanos y no humanos) y lugares, de modo que dichas presencias no pueden reducirse ni a representaciones culturales específicas sobre la muerte ni a propiedades que son aprehensibles objetivamente en el lugar mismo. Más bien, dichas presencias emergen de la constante interacción en la que participan gente y lugares. Tal participación puede entenderse en términos fenomenológicos. Objetando la suposición de que los lugares son neutrales metafísicamente (i. e., son un sustrato vacío al que se le adjudican ciertos predicados culturales), el filósofo Edward Casey (1996) argumenta que estos congregan o acopian cosas (objetos, cuerpos, pero también sentidos, recuerdos y sensaciones). Acopiar significa el poder que tienen los lugares tanto para alojar dichas cosas como para definir la posición o forma misma en que están alojadas: "Alojar de la manera en que lo hacen los lugares es tener un control peculiar sobre lo que se presenta (y se representa) en un lugar determinado. No solo los contenidos, sino el mismo modo de contención son sostenidos por los lugares”3 (25). En otras palabras, el poder de acopio de un lugar es su capacidad de imprimirles cierto sentido a las cosas. Aquí sentido ha de entenderse en sus dos acepciones: significado - "los contenidos”-y dirección - "el modo de contención”- Esta capacidad de acopio nos lleva a considerar que el sentido no es siempre el resultado de un proceso volitivo a través del cual la agencia humana impone orden y significado al mundo, sino que hay algo en el mundo mismo que nos invita a experimentar las cosas de 
la manera en que lo hacemos. La idea de que los lugares están dotados con cierta intencionalidad operativa (Merleau-Ponty [1945] 2002, 208) o de que ellos proveen sentido (significado y telos) es una invitación a considerar que no siempre hay arbitrariedad entre las particularidades de un lugar y la forma en que este se habita y se representa. Otro ejemplo etnográfico puede arrojar luces sobre el tipo de poder que adscribo a Caño Claro.

Durante algún tiempo, mi trabajo en el Bajo Atrato consistió en documentar las violaciones de los derechos colectivos causados por el despojo de tierras asociado con los cultivos de palma aceitera en Curvaradó. Documentar los impactos significaba describir el tipo de vida que la gente tenía en sus territorios antes del desplazamiento forzado, por lo que recopilamos muchas historias de vida, así como testimonios sobre cómo eran los caseríos y las actividades de las comunidades antes de la Operación Génesis lanzada por el Ejército colombiano en $1997^{4}$. Pero no fue sino hasta la visita que hicimos con varios líderes de la región a las zonas afectadas que los efectos del daño adquirieron toda su dimensión. En particular, recuerdo cómo muchos de los líderes con los que ya había conversado empezaron a evocar nuevos detalles sobre sus vidas cotidianas. A medida que recorríamos las incontables hileras de palmas que se extendían una y otra vez en lontananza, varias de estas personas distinguieron los lugares donde alguna vez estuvieron sus casas, sus cultivos, sus centros comunitarios, sus escuelas, sus canchas de fútbol. No fue su capacidad de reconocer un lugar que había sido puesto patas arriba por los palmicultores lo que más me sorprendió, sino el hecho de que, conforme lo recorríamos, empezaron a evocar recuerdos e historias que antes no habían compartido. En un sentido no solo metafórico, fue como si el lugar estuviera reteniendo esos recuerdos dentro de sus contornos y hubiera estado esperando la presencia de sus antiguos pobladores para emitirlos. También podría decirse que fue en virtud de su presencia allí que esos recuerdos emergieron. Después de ese recorrido empecé a preguntarme cuánto de esos recuerdos pertenecían a la gente y cuánto al lugar.

Mientras que el enfoque fenomenológico se acerca a los cuerpos y lugares no como entidades discretas y autocontenidas sino porosas y fluidas, e incluso en algunos casos se les considera eventos (los lugares suceden puesto que, además

4 La Operación Génesis fue una operación contrainsurgente liderada por la XVII Brigada del Ejército y secundada por los paramilitares de las ACCU, que produjo el desplazamiento forzado de más de 7.000 habitantes de las comunidades afrocolombianas del Bajo Atrato (para ampliar, véanse CIJP [2005]; Observatorio del Programa Presidencial de Derechos Humanos [2003]; Valencia [2013]). La flagrante violación de los derechos de las comunidades locales cometida durante este operativo llevó a que la Corte Interamericana de Derechos Humanos condenara al Estado colombiano en el 2013. 
de ser el resultado de los procesos sociohistóricos a través de los cuales la gente los construye, son también fuerzas capaces de orquestar experiencias particulares), la teoría de los afectos permite entender la presencia de los espíritus de la mala muerte en Caño Claro como un tipo de propiedad emergente, esto es, como una existencia que se desprende de la interacción entre personas y lugares cuyas respectivas biografías están enmarcadas por episodios de profunda violencia. Con ello quiero decir que, si bien los espíritus que habitan Caño Claro sobrevienen como resultado de una mala muerte, la forma en que se revelan no está disociada de las cualidades que son ahora inherentes al lugar. En su etnografía sobre las relaciones que las familias turco-chipriotas tejen con las casas y objetos abandonados por sus habitantes originales luego de la partición de Chipre en 1974, la antropóloga turca Yael Navaro-Yashin describe cómo estos lugares están ahora inmersos en un ambiente melancólico. Pero melancolía no es solo la forma en que las familias relocalizadas hablan de los lugares y pertenencias que tuvieron que abandonar por los greco-chipriotas, es también un tipo de atmósfera que envuelve al lugar y que afecta a los turco-chipriotas que fueron forzados a habitarlo (Navaro-Yashin 2009, 11). Para ella, esta atmósfera melancólica es un tipo de afecto que no puede ser localizable ni en los objetos mismos ni en las representaciones que se hace la gente. Más bien se trata de algo que emerge de la interacción entre unos y otros, es decir, no es una propiedad que pertenezca a los objetos mismos ni una mera idea que la gente impregna en su mundo material. Al tratar la melancolía del lugar como un afecto, Navaro-Yashin (2012) vuelca su atención etnográfica hacia la forma en que un ambiente en ruinas logra descargar una energía particular y cómo las subjetividades de sus habitantes están envueltas y modeladas por las ruinas que los rodean (172).

La conceptualización de ciertas fuerzas o energías en términos de afectos que son coconstituidos por la gente en diálogo con sus mundos circundantes resulta bastante útil para entender lo que sucede en Caño Claro. Por un lado, nos ayuda a pensar el tipo de realidad que los espíritus hacen presente como algo más que un sistema representacional creado por una cultura específica. En otras palabras, hay algo en la naturaleza de estos espíritus que no pertenece a la gente sino al mundo mismo. Por otro lado, nos invita a considerar aquellos otros efectos intangibles de la guerra que quedan igualmente impregnados en ciertos lugares y que no pueden ser reparados por las vías habituales de la justicia transicional (por ejemplo, la reparación de los derechos humanos que fueron violados). Ambas cosas - coemergencia y prevalencia - me llevan a sugerir que hay lugares que necesitan ser considerados no solo como el espacio donde ocurrieron ciertos eventos violentos, sino también como medios a través de los cuales la violencia es performada, recordada y actualizada. 


\section{Tierra rara y muertes malas}

En Caño Claro el ataque de la guerrilla no acabó con la presencia paramilitar, más bien la prolongó de otra manera, puesto que los espíritus de los combatientes que murieron allí se convirtieron en almas en pena atrapadas en ese lugar. Estos espíritus buscan resolver un drama existencial, a saber, su paso al más allá. Los espíritus de la mala muerte están contenidos en el lugar, como lo demuestra el hecho de que los encuentros con ellos suceden siempre en las inmediaciones del antiguo campamento. Doña Flora me contó la vez que escuchó voces extrañas mientras se encontraba pescando en las bocas del caño. Estaba en su champa ${ }^{5}$ y oyó murmurios provenientes de la orilla. Pensó que se trataba de su vecino que pasaba por ahí, pero mientras continuaba concentrada en su oficio alguien le arrojó un trozo de tierra que casi le golpea la cabeza. Enojada miró hacia la orilla del río y recriminó a quien le arrojó aquello, pero no vio ni escuchó a nadie. Terminó la pesca y antes de regresar a casa decidió pasar donde su vecino a recriminarle por la broma pesada. El vecino le aseguró que él no había sido, que ese día lo había pasado limpiando sus cultivos. Fue entonces cuando doña Flora se dio cuenta de que las voces que oyó y el pedazo de tierra que cayó en su champa no eran de origen humano: "En ese lugar asustan”, me dijo. "Allá hay espíritus en pena” (entrevista, septiembre del 2016). Me dijo que una de las cosas que más le había sorprendido era que el aspecto, el color y la consistencia del pedazo de tierra que le habían arrojado no correspondían en nada al tipo de tierra que se encuentra en la región. Veo en la apariencia de esa tierra un índice irrefutable de la naturaleza de esas presencias fantasmales: es una tierra que no pertenece al lugar, es un elemento foráneo, tal y como lo fueron los paramilitares que ocuparon el Bajo Atrato (recuérdese que la cédula que encontró doña Aleyda era de un joven mercenario que terminó muriendo lejos de su tierra natal). Además, los eventos que siguieron a sus muertes dejaron a los espíritus de estos combatientes sin la posibilidad de encontrar un pedazo de tierra adecuado donde descansar. Gente foránea que murió en una tierra extraña y sin debido entierro. En ese pedazo de tierra arrojado a doña Flora parece haber una solicitud existencial: estos muertos necesitan retornar a sus propias tierras o, al menos, encontrar un lugar en el que puedan descansar en paz sus restos y sus espíritus.

Antes de describir las relaciones que las comunidades de Caño Claro mantienen con estos espíritus, quisiera señalar algunos aspectos metafísicos de la muerte, tal y como la refieren las comunidades afrocolombianas del Pacífico. 
Quizás una de las características más importantes es que la muerte no sucede en un solo instante, es decir, además de ser un evento físico de irreversibles consecuencias, implica un proceso ontológico de paulatina transformación. Por ejemplo, suele ser presagiada: lastimeros aullidos de perros en medio de la noche, el canto del guaco en la selva (Serrano 1994), hormigas que entran y salen de la cocina (Velásquez [1961] 2000), los intempestivos movimientos de las hojas de la palma de cristo. Este tipo de presagios dan cuenta de la muerte como un proceso más que como un evento. Incluso antes de que el cuerpo manifieste señales de enfermedad o decadencia, el espíritu puede empezar a vagar en sueños, a recorrer diferentes lugares o a visitar familiares. La vida entonces no es simplemente algo que se tiene o no, más bien es una propiedad que existe en determinadas cantidades. Dormir y soñar, por ejemplo, son instancias que se parecen a la muerte, pues es cuando el espíritu deja de habitar el cuerpo y se va a viajar por el mundo. Se dice entonces que alguien puede morir de a poquitos, no tanto por la progresiva pérdida de facultades físicas o mentales, sino porque hay partes del espíritu que se desprenden del ser incluso antes de la muerte física. De manera similar, después de que el cuerpo cesa de ser un repositorio de vida, hay partes del ser que no dejan este mundo a menos que se lleven a cabo los rituales apropiados. Además de cumplir la función sociológica de reforzar lazos comunitarios y valores colectivos, estos rituales pueden entenderse como prácticas de cuidado que los vivos prodigan a los muertos y a sus espíritus con el fin de ayudarlos a alcanzar el más allá. Cuando dichos cuidados no pueden realizarse, existe entonces la posibilidad de que el espíritu de un muerto no abandone este mundo y se quede vagando entre los vivos, ya sea habitando los sitios que el muerto prefirió en vida, o quizás rondando en la selva, en cementerios u otros lugares considerados liminales.

Existen buenas y malas muertes. En Bajo Atrato una buena muerte ocurre cuando se está rodeado de la familia y cuando los dolientes acompañan a sus muertos a través de los rituales funerarios (Quiceno 2015; Serrano 1994; Velásquez [1961] 2000). Una mala muerte es aquella que sucede repentina o violentamente, lejos de casa o de la comunidad, o aquella que sobreviene cuando no se ejecutan los debidos ritos de duelo y entierro. Prácticas características del Pacífico colombiano como las novenas - las reuniones de nueve días en las que, a ritmo de juegos de cartas, dominó y alabaos ${ }^{6}$, tanto familiares como amigos acompañan a los dolientes - tienen como fin acompañar al espíritu del difunto durante el periodo liminal en el que este se prepara para dejar el mundo de los 
vivos. Uno de los momentos más solemnes ocurre en la madrugada del último día, cuando el espíritu cesa de recorrer sus pasos y se hace presente en el altar que sus familiares le han construido. Es el momento del último adiós, de la partida definitiva del muerto: una partida marcada por el desmantelamiento del altar alrededor del cual la gente se congregó durante la novena (Losonczy 2006; Serrano 1994; Velásquez [1961] (2000); Whitten 1974). De esta manera, ser enterrado, llorado y acompañado durante los ritos fúnebres son elementos que pueden distinguir una buena muerte de una mala. Por el contrario, el espíritu de quien sufre una muerte repentina, violenta o lejos de su propia tierra y gente enfrenta problemas para recoger sus propios pasos, más aún si no recibe los adecuados ritos fúnebres. Puede entonces quedarse morando en aquellos lugares que, como la selva o el cementerio, marcan la frontera entre los espacios humanos o mansos y los espacios bravos. En el caso de las muertes violentas, estos espíritus suelen quedarse habitando los sitios en donde la muerte los sorprendió. Este es el principal problema de los combatientes que murieron en Caño Claro: ninguno de ellos gozó de los acompañamientos funerarios que pueden tornar su mala muerte en una buena. Estas muertes, así como las de todos aquellos cuyos cuerpos no fueron recuperados jamás, representa un problema para los vivos que habitan los lugares marcados por esos eventos violentos: por un lado, estos muertos no pueden abandonar totalmente el mundo de los vivos y están obligados a vagar entre este mundo y el más allá, hasta tanto sus muertes no sean honradas adecuadamente; por el otro lado, la gente está obligada a lidiar con estas presencias y con el espanto que sus manifestaciones representan.

La muerte violenta, tal y como se ha explorado en varios trabajos antropológicos que abordan el sufrimiento, duelo o trauma en contextos de violencia política, deja una huella profunda que trasciende la naturaleza del evento en sí mismo (Das 1997; Hertz [1909] 1960; Perera 2001). Por definición, la muerte violenta transgrede el orden social y cultural que se le asigna a una muerte ordinaria, de manera que dichas muertes son de difícil trámite psicológico y simbólico. Espíritus como los que habitan Caño Claro no son sino el resultado de una mala muerte. Estas presencias pueden definirse como manifestaciones incorpóreas de los muertos, impresiones sensoriales duraderas que dejan eventos trágicos en ciertos lugares. La adhesión a ciertas zonas, su manifestación dentro de específicos límites espaciales es lo que hace que estos espíritus sean considerados seres que pertenecen al mundo y no simples percepciones subjetivas que no corresponden con la realidad. Tales espíritus representan además una suerte de incertidumbre ontológica o profunda inquietud existencial porque son un estado que cualquier persona puede alcanzar. Como son una forma de devenir 
indeseable, representan un tipo de falla, una anomalía que interrumpe el fluido normal de la vida y del tiempo. Interrumpen el ritmo propio de la vida porque permanecen en un estado liminal, en un umbral entre el mundo de los vivos y el de los muertos. Desvertebran también el ritmo del tiempo porque se obstinan en aparecer y reaparecer, son como una fijación, "un evento terrible condenado a repetirse una y otra vez” (Del Toro 2001). Tomo prestadas las palabras que el director mexicano Guillermo del Toro pone en boca del protagonista de su película El espinazo del diablo cuando este se pregunta qué es un fantasma: “[E]s un instante de dolor, quizás algo muerto que parece por momentos vivo aún, un sentimiento suspendido en el tiempo, como una fotografía borrosa, como un insecto atrapado en ámbar”. Las presencias de Caño Claro son exactamente eso, afectos o impresiones en un estado de eterno retorno, que oscilan siempre en el mismo tiempo y espacio, seres ambiguos que contienen y de los que emanan los afectos de aquellos que sufrieron una mala muerte. Al ser instancias de dolor suspendidas en el tiempo, una y otra vez se manifiestan, para reclamar atención a su muerte y hacer presente el sufrimiento que ella les produce. Por ello estas presencias no participan propiamente del mismo tiempo histórico de los vivos. El suyo no es un tiempo que fluye en trayectoria lineal sino en rotación espiral alrededor del mismo evento. Pero, al hacerlo, comparten conexiones parciales con el discurrir del tiempo de los vivos.

Los espíritus de quienes murieron mal no pueden sino manifestarse de manera disruptiva. Pero su irrupción violenta en los lugares y en la vida cotidiana de la gente no es necesariamente intencional. Más bien se trata del resultado que su mera presencia provoca: cuando estos espíritus se manifiestan producen un tipo de distorsión en las cualidades del lugar, una alteración en el sitio y una suerte de bache en el flujo temporal de los vivos. Comparo los efectos que estas presencias provocan con lo que hacen las olas y ondas de los botes que suelen navegar ríos como el Curvaradó. De la misma manera en que el paso de estas embarcaciones ondula la superficie del río, las manifestaciones de los espíritus dejan una suerte de trayectoria en el lugar. La propagación de estas olas y ondas en el río o el tipo de distorsiones y trayectorias que provocan los espíritus son de alguna manera violentas por el mero hecho de interrumpir o alterar algo que de otra manera habría permanecido quieto, llano.

Estos espíritus representan también otro tipo de fracaso existencial: son la antítesis de andar, embarcar y viajar. En el Bajo Atrato la vida está asociada al movimiento: ríos, animales, nubes y árboles tienen vida porque se mueven. La falta de movimiento se asocia entonces con aquello que carece de vida: aguas estancadas, piedras y palizadas, por ejemplo (Velásquez [1961] (2000). Mientras 
que los vivos pueden embarcarse y viajar, espíritus como los de Caño Claro están fijos en un lugar. Este tipo de estancamiento se encuentra en las antípodas de los valores positivos que las comunidades afroatrateñas asocian al hecho de viajar y embarcar. Embarcar significa navegar los ríos, ir de una comunidad a otra a visitar amigos y familiares (Quiceno 2015); es ir y volver con el fin de nutrir y extender lazos de parentesco (Friedemann 1974). Viajando de un río a otro es como se conectan los caseríos y las comunidades, como se participa de la vida económica y de las actividades colectivas (Escobar 2008; Oslender 2004, 2008); embarcando y viajando es como se cultivan valores e identidades comunitarias; andando es como se conoce e interactúa con el territorio; yendo y viniendo entre comunidades es como la mayoría de personas adquieren las destrezas que les permiten participar de la vida social, productiva y cultural de la región. A través del andar, embarcar y viajar es como se cultivan sentidos identitarios y territoriales. Como los espíritus de Caño Claro no pueden viajar, ellos no conocen ni aprenden sobre el mundo (Whitten 1974). En este sentido, carecen de voluntad puesto que no pueden decidir a dónde ir. La manera extraña y siniestra a través de la cual se relacionan con el mundo no es moralmente buena ni mala. Más bien estos espíritus hacen lo único que pueden hacer: quedarse estancados en los lugares donde murieron hasta que les sea redimido el trágico destino que los atrapó y confinó allí. Andar, al igual que embarcar, es vivir y ejercer voluntad propia, pero estas posibilidades están bloqueadas para los espíritus de quienes sufrieron malas muertes.

Dicho esto, pueden entenderse mejor las interacciones que los habitantes de Caño Claro mantienen con estos espíritus. Doña Aleyda, por ejemplo, me contó que ella había tenido no uno sino tres encuentros con ellos. La última vez que los topó, reaccionó con furia:

El día que me asustaron yo empecé a insultarlos, a decirles un poco de cosas: que por ellos uno ha pasado tanto trabajo, que por ellos uno perdió tantas cosas. Uno ya está cansado, imagínese uno tener que volver a romper aquí nuevamente. Ese día yo hablé un poco de disparates, sola, que parecía una loca: "Por ustedes se nos puso el caldo tan espeso; ustedes no trabajaban ni dejaban trabajar”. Y vea que ahora que retorné a mis tierras ellos ya no dejan otra vez trabajar. (Entrevista, septiembre del 2016)

Doña Aleyda, como tantos otros campesinos de la región, es una víctima de la violencia paramilitar. Soportó no solo el desplazamiento forzado y la pérdida de sus bienes sino también la desaparición de familiares y la muerte de su propio esposo, quien, dice ella, terminó muriendo de pena moral luego del desplazamiento. Su insulto es un reclamo contra los causantes de su sufrimiento. Doña 
Aleyda regresó a su tierra en compañía de sus hijos, nueras y nietos. Al retornar, encontraron sus casas destruidas y el monte tomando posesión de lo que alguna vez fueron sus sementeras. El retorno implica un arduo trabajo de reconstrucción y recuperación de la base económica campesina, tarea que doña Aleyda describe como un “romper de nuevo”, un recomenzar que asevera es aún más duro a causa de su edad. A estas dificultades se agrega la presencia de los espíritus en pena, cuyas constantes manifestaciones se tornan incluso fastidiosas, como lo fue el caso de la tierra arrojada a doña Flor. Es la incomodidad de realizar tareas cotidianas y la transformación de las cualidades del lugar lo que se refleja en la afirmación de que estos espíritus "no dejan otra vez trabajar".

Aunque estos espíritus pueden llegar a ser molestos, la gente ha encontrado maneras de lidiar con ellos. En primer lugar, no hay que temerles puesto que, como me explicaron, no buscan causar perjuicio a los vivos, sino llamar la atención sobre su situación y demostrar su propio dolor. Después de todo, son almas en pena que buscan consuelo o solución al drama de no poder pasar al más allá. En el Bajo Atrato, como en muchas otras regiones latinoamericanas, la figura del ánima en pena está asociada a la de un espíritu que no logra ascender al cielo. Como la muerte violenta suele ser su etiología más común, las ánimas esperan de los vivos un acompañamiento, una acción que les permita transitar exitosamente al más allá. Insultos como los de doña Aleyda no quieren decir que la gente en Caño Claro sea indiferente al sufrimiento de estos espíritus, más bien les resulta difícil empatizar con quienes en vida les causaron tantos dolores y pérdidas.

Con el fin de situar mejor las prácticas y los dilemas que enfrentan las comunidades de Caño Claro, discutiré el trabajo de dos antropólogos que han documentado las experiencias de algunas comunidades con los espíritus de aquellos que sufrieron una mala muerte en contextos de violencia política. En su trabajo en Sri Lanka, Sasanka Perera (2001) describe cómo después de los combates librados entre el Frente de Liberación del Pueblo (Janata Vimukti Peramuna [JVP]) y las fuerzas contrainsurgentes del Estado, muchos campesinos han reportado la presencia de los espíritus de quienes murieron durante los cruentos días de la guerra. Según Perera, aquellas personas que sufrieron algún tipo de experiencia traumática son las más proclives a encontrarse con estos espíritus y, en algunos casos, a ser incluso poseídos por ellos. Al igual que en Caño Claro, los encuentros con estos espíritus tienen lugar en los sitios asociados con actos de extrema violencia: edificios en los que combatientes o personas señaladas como simpatizantes de la guerrilla fueron torturados, los campos en los que fueron incineradas decenas de cuerpos, los ríos y pozos en donde se ahogaron civiles en su intento por esconderse. Perera (2001) ve en la naturaleza de esos encuentros 
"un referente simbólico al problema del cargo de conciencia que acompaña tanto a los sobrevivientes como a los perpetradores de esta violencia” (162). Según él, además de estar asociado a los sentimientos de culpa que suelen embargar a los sobrevivientes de actos violentos, este cargo de conciencia se relaciona con la impotencia de los sobrevivientes y familiares de las víctimas por no haber podido hacer nada que impidiera estas trágicas muertes. En este sentido, las experiencias con estos espíritus resultan ser el despliegue de

mecanismos a través de los cuales una comunidad recuerda a la gente que murió, un mecanismo que ayuda a la gente a poner en perspectiva tanto las pérdidas colectivas como el pasado violento. Estos recuerdos son construidos como expresiones de culpa de los vivos hacia los muertos, representan un deseo de justicia y venganza, así como la necesidad de aliviar el sufrimiento sobrenatural de aquellos que tuvieron muertes antinaturales. (197)

En otras palabras, espíritus, posesiones y lugares encantados no son más que epifenómenos de un trauma individual y colectivo, es decir, representaciones culturales a través de las cuales una conciencia colectiva que no ha sanado expresa tanto sus aspiraciones de justicia como la necesidad de preservar la memoria de lo sucedido. Si bien comparto la idea de que los espíritus y el embrujo asociado a ciertos lugares son expresiones de una violencia cuyas consecuencias no han logrado ser superadas, el enfoque de Perera (2001) tiende a patologizar estos fenómenos, al asumirlos exclusivamente como expresiones provenientes de los mundos internos de la gente. Así, argumenta el autor, una vez a las comunidades se les provea de medios psicosociales "para enfrentar las experiencias del pasado” (170), los espíritus simplemente desaparecerán y los lugares que estos habitan dejarán de estar encantados. Mi punto es que este enfoque traslapa el trauma y lo que el autor llama actividad supernatural (197), es decir, hace del sufrimiento colectivo y de los espíritus de los muertos una misma cosa. Además de reificar fronteras entre la realidad y la creencia, este enfoque contradice uno de los principios discutidos al comienzo de este texto, a saber, que los lugares no están simplemente hechos de las historias que la gente crea sobre ellos sino que también participan, de una manera muy concreta, en la generación de sentidos, experiencias y sensibilidades. Estas capacidades agentivas que tienen los lugares se amplifican en contextos de sufrimiento y violencia. Veo entonces que, más que mecanismos creados por las comunidades para reconciliarse con un pasado violento y aliviar su cargo de conciencia, en Caño Claro los espíritus y el embrujo de ciertos sitios resultan más bien parte de la naturaleza misma del mundo y de cómo la violencia permanece incrustada y actualizada en cuerpos y lugares. 
Me explico. En uno de sus textos más influyentes, Veena Das (1998) discute cómo "tengo dolor" no es simplemente una declaración sobre un hecho sino la manera en que el hecho mismo se presenta y se hace inteligible, es decir, es la forma en que el dolor adquiere expresión. El punto es que el dolor y el sufrimiento no son solo manifestados bajo ciertas fórmulas sino que estas experiencias adquieren la forma y el sentido que les dan los medios a través de los cuales se expresan. En otras palabras, los encuentros con espíritus y las experiencias con lugares encantados no son simplemente expresiones culturales de una experiencia traumática, sino que espíritus y lugares encantados participan y modelan la manera en que la gente asume el sufrimiento y concibe estrategias para superarlo.

Hay otro aspecto en el que las experiencias de Sri Lanka y Caño Claro pueden ser contrastadas. En esta última, la gente no está siendo testigo de las apariciones de los espíritus de personas que pertenecieron a sus comunidades. Todo lo contrario, los espíritus de los perpetradores son los que habitan el lugar, es decir, los de aquellos que, como describe doña Aleyda, son los responsables de todo lo que perdieron las comunidades. Esto es fundamental para entender por qué estos espíritus no pueden ser interpretados como meros "reflejos de la conciencia angustiada de la comunidad" (Perera 2001, 170), ya que para los habitantes de Caño Claro resulta difícil sentir algún tipo de remordimiento por lo sucedido a quienes causaron su desplazamiento forzado y la desaparición de tantos seres queridos. El problema de empatizar con estos muertos puede verse en el tratamiento que doña Aleyda y sus vecinos les prodigan a los restos mortales que han encontrado: llegan incluso a usarlos para gastarse bromas. Quizá bajo otras circunstancias el cráneo de un muerto recibiría otro tipo de consideraciones, pero aquí la identidad de esos muertos sigue asociada al sufrimiento colectivo de las comunidades locales.

No obstante, la aparente falta de empatía hacia el sufrimiento de los espíritus que erran en Caño Claro no significa que la gente no sea consciente de las necesidades de estos seres. Al contrario, tras múltiples encuentros en los que las familias han discutido qué hacer con esos muertos, han concluido que, a menos que esos restos sean desenterrados y entregados a sus familiares para que les prodiguen adecuadas sepulturas, los espíritus van a continuar habitando el lugar y causando dificultades para vivir y trabajar en Caño Claro. En este sentido, las experiencias de estas comunidades pueden ser comparadas con las relaciones que el antropólogo surcoreano Heonik Kwon (2008) describe entre vivos, ancestros espirituales y los fantasmas de la guerra en Vietnam.

Íntimamente relacionados con las tradiciones budistas y su reverencia a los ancestros, los fantasmas de aquellos que murieron en la guerra en Vietnam 
son considerados el resultado de una muerte violenta ocurrida lejos de casa. Los términos para referirse a estos fantasmas (nguoi ngoai) son similares a los empleados para aludir a los extranjeros, puesto que a estos fantasmas se les considera intrusos en el mundo de los vivos (Kwon 2008, 20). Según Kwon, los fantasmas de la guerra tienen una doble condición liminal: por un lado, no han dejado del todo el mundo de los vivos ni han sido integrados al mundo de los ancestros fallecidos; por el otro, no están completamente separados de los lugares en los que murieron, por lo que no pueden ser incorporados al espacio positivo y trascendental que la gente confiere a sus muertos: "La miseria de ser un fantasma es de hecho el resultado de no tener un lugar específico con el cual relacionarse, es decir, un lugar en el que sus identidades sean recordadas y su sufrimiento sea consolado" (152). En contraste con la interpretación etic sobre la presencia de espíritus en Sri Lanka, el caso vietnamita privilegia el tipo de cuidados que se les prodigan a estos fantasmas, porque - al igual que en Caño Claro- son considerados seres que pertenecen al mundo y no simplemente el resultado de relaciones traumáticas con la realidad. Estos espíritus constituyen una preocupación ontológica ya que la gente en Vietnam entiende que un adecuado respeto hacia los muertos es condición fundamental para el bienestar y la prosperidad de los vivos.

Al considerar que los fantasmas padecen la doble alienación de, por un lado, tener que errar entre los márgenes del mundo de los vivos y el más allá, y por el otro, de carecer de un lugar adecuado donde anclar su memoria (Kwon 2008, 20), algunas comunidades en Vietnam conducen una serie de rituales para aliviar el sufrimiento de estos espíritus: se les construyen altares y tumbas, se les dirigen oraciones y ofrendas en los lugares asociados con sus apariciones. En algunos casos, la gente logró identificar a los familiares de estos muertos, lo que permitió la ejecución de apropiados rituales funerarios. Pero cuando esto no es posible, la gente crea lazos de parentesco ficcional con estos espíritus. A través de dichos lazos, los espíritus son incorporados al ámbito doméstico de los ancestros, y como tales se vuelven objeto de respeto y reverencia. Los fantasmas se convierten así en espíritus que son tratados simultáneamente como parientes y deidades. Una vez adoptados, estos espíritus aspiran a demostrar a sus nuevas familias que su adopción ha sido productiva e interceden ante deidades más poderosas por el bienestar material de sus nuevas familias.

Esta manera de relacionarse con los fantasmas de la guerra en Vietnam comparte algunas similitudes con el tratamiento que las comunidades de Caño Claro aspiran prodigarles a los espíritus. En ambos contextos se entiende que la 
aparición de estos seres ${ }^{7}$, cuyo estatus ontológico y existencia no dependen solo de las creencias de las personas, está relacionada con su imperante necesidad de encontrar adecuada sepultura, por lo que la gente no puede permanecer indiferente a esta demanda. Las circunstancias violentas de las muertes no solo confinan estos espíritus a los lugares en que murieron, sino que también, como ya lo apunté, los ciñen a un particular ritmo del tiempo, condenándolos a repetir una y otra vez su dolorosa desaparición. De este modo, el objetivo de sepultarlos, orarles o realizarles ofrendas es liberarlos de su lúgubre condición e insertarlos en el flujo del tiempo. De una u otra manera la gente que convive con estos espíritus se interesa en aliviar su sufrimiento, puesto que el no recordarlos o la indiferencia de los vivos agrava su situación. Así, existe en ambos lugares una consideración ética hacia los muertos. Sin embargo, el principal problema en Caño Claro es que sus habitantes no quieren ser quienes realicen estos actos de memoria y piedad. La razón principal, me parece, es que estos muertos continúan siendo asociados con el dolor y el sufrimiento de un pasado muy reciente. En Vietnam las identidades de estos espíritus ya no son relevantes puesto que la gente le da ahora poca importancia al bando al que pertenecieron estos muertos. Según uno de los devotos entrevistado por Kwon (2008), los muertos han olvidado la ideología que los condujo a la muerte: "[A] los fantasmas de la guerra no les importa ya la guerra [...] en el cementerio ya no existe la enemistad" (27). Entonces, sin importar si los fantasmas pertenecen a los soldados vietnamitas o estadounidenses, si fueron combatientes del Viet Cong o del ejército oficial, la principal preocupación es que todos ellos sufrieron un tipo de mala muerte y han sido olvidados por sus seres queridos. Al final de cuentas, lo más importante son los actos de memoria y conmemoración porque, como afirma otra de las personas entrevistadas por el autor: "los muertos ya no pelean entre sí. Ellos ni siquiera sienten ya rabia. Lo único que quieren es ser recordados. Quieren que al menos alguien sepa el sufrimiento por el que han tenido que pasar" (40). Una de las razones por las que comunidades rurales en Vietnam y Colombia se relacionan de manera tan disímil con estos muertos de la guerra radica en aquello a lo que Mircea Eliade (1971) llamó el terror a la historia, es decir, el miedo que provoca enfrentarse con la herencia que deja tras de sí la inexorable marcha de los eventos y del tiempo. Basta recordar que la guerra en Vietnam terminó hace más de cuarenta años mientras que las heridas del conflicto armado en Colombia siguen aún abiertas.

7 Considero que estas presencias tienen su propio estatus ontológico, muy distinto al de otro conjunto de seres materiales, pero por ello no son menos seres que, digamos, una culebra o un jaguar. Para mí son seres regidos por una serie de reglas muy específicas, pero seres al fin al cabo, puesto que su estatus y existencia no dependen solo de las creencias de la gente. 
Sin embargo, como discutiré en la siguiente sección, hay otras maneras en que las comunidades de Caño Claro han establecido conexiones empáticas con los espíritus que merodean su lugar.

Antes de finalizar este apartado quisiera sugerir la posibilidad de que aquellos que murieron en Caño Claro pueden, de hecho, mejorar las condiciones materiales de los vivos. Esta posibilidad fue insinuada por doña Aleyda, cuando manifestó su intención de jugar la lotería con el número de la cédula que encontró. Dado que esa cédula pertenece a alguien que no ha dejado del todo este mundo pero que no ha entrado completamente al otro, se presume que su portador puede traer buena suerte. Este tipo de espíritus representan entonces un mensaje ambiguo de sufrimiento y de deseo de superar ese sufrimiento: merodean en pena por este mundo, pero su destino puede ser redimido si logran proveer buena suerte a quienes se interesan por ellos. La conexión entre ánimas en pena y prácticas mágicas ha sido ya explorada por Michael Taussig (1992), quien afirmó que el embrujo o el encanto que resulta de quienes sufrieron una muerte violenta siempre contiene un coeficiente de fuerza mágica (27). La creencia en las fuerzas mágicas de algunos muertos puede observarse en muchas otras regiones del país. Se trata de plegarias que mucha gente dirige a los muertos sin identificar y en las que ruegan ayuda en temas de empleo, dinero, amor y salud. Por ejemplo, los lunes en el Cementerio del Sur en Bogotá, muchos peregrinos visitan las tumbas de los NN y les llevan flores, velas e incluso música para solicitar a estas ánimas que intercedan por ellos en la esfera divina y les favorezcan su suerte en este mundo (Trujillo 2012). De manera similar, algunos habitantes de Puerto Berrío empezaron a rescatar los cadáveres que encontraban en el río Magdalena y les proveyeron tumbas en el cementerio local. Estas personas cuidan de los espíritus ofreciéndoles misas y oraciones, con la esperanza de que las ánimas puedan cumplirles un milagro (Echavarría 2013; Nieto 2012). Aunque en Caño Claro los espíritus están lejos de ser venerados, está la posibilidad de que vivos y muertos establezcan un acuerdo mutuamente beneficioso: a través de los rituales para recordarlos, el sufrimiento de las almas en pena puede ser aliviado y, a cambio, ellos pueden intervenir en la esfera divina para mejorar la situación material de los vivos. 


\section{Una paz en el más allá para sanar el más acá}

Con frecuencia, la presencia de grupos armados en determinadas áreas crea una serie de fronteras invisibles que, a su vez, refuerzan un repertorio de estigmas sobre la población civil y sus supuestas lealtades. La gente de Caño Claro no fue la excepción, pues a causa del ataque al campamento paramilitar se les asoció con la guerrilla. Doña Lucrecia, una mujer que ocasionalmente contrata hombres en la vecina ciudad de Belén de Bajirá para que le ayuden durante la temporada de cosecha de maíz y arroz, me contó cuán difícil es encontrar trabajadores que acepten venir a su finca una vez se enteran en dónde está localizada. El rumor es que la zona fue y sigue siendo bastión de la guerrilla, aun cuando fueron los paramilitares y no esta última quienes establecieron su campamento en la zona. Las consecuencias de lo que pasó se extienden entonces como un estigma sobre los habitantes de Caño Claro, a tal punto que la mala fama del lugar ha desmotivado a algunas familias a retornar de manera permanente a sus tierras. Las secuelas de lo sucedido se expresan entonces en dos diferentes (pero no opuestas) dimensiones: hacia afuera del lugar, en el sentido de crear un prejuicio sobre los habitantes de la zona; y hacia adentro, puesto que ha obligado a los habitantes locales a tomar medidas para lidiar con esas presencias fantasmagóricas. Aunque parecen dos registros diferentes, ambos expresan un conjunto de efectos públicos; ambos obligan a la gente a tomar acción y requieren expresar obligaciones, valores, relaciones y formas de representación; ambos están relacionados con la memoria y sus efectos en la vida diaria; ambos tienen que ver con cómo conectar y regular relaciones entre comunidades - por un lado, entre las familias de Caño Claro y las comunidades vecinas; por el otro, entre las familias del lugar y los espíritus que allí pululan-. En otras palabras, ambas dimensiones hacen parte de una misma manera de concebir y hacer política: una política en la que lo fundamental no es la regulación de relaciones de poder sino la promoción de relaciones entre diferentes formas de ser y habitar el mundo.

Uno de los problemas que afecta a Caño Claro es la incertidumbre. No muchos saben lo que pasó y quienes creen saberlo no tienen certeza sobre cuánta gente murió y mucho menos sobre sus identidades. Estos espíritus se convirtieron en almas en pena cuyo tránsito al más allá se ha visto comprometido precisamente porque sus familiares ignoran el destino corrido por estos muertos. Lejos de sus seres queridos y enclavados en un sitio que no es su tierra, estos espíritus están condenados a habitar allí y a repetir el dolor del olvido. Su inconsolable estado de abandono es capturado por la expresión que describe lo que pasó con sus cuerpos: se los comieron los goleros, es decir, se volvieron carroña. Es este estado 
de abandono lo que ha comprometido sus almas, las mismas que, a juzgar por las prácticas de algunos habitantes locales, merecen cierto tipo de consideraciones, independientemente de las afiliaciones políticas que hayan tenido en vida. Al menos este es el fundamento ético que parece desprenderse de la propuesta realizada por las comunidades de Caño Claro para sanar su territorio. Muchos argumentan que si los restos son identificados y entregados a sus respectivas familias, los espíritus que moran allí van a descansar en paz y a desaparecer. "Lo que se necesita”, me explicó Ovidio, “es que se reconozca públicamente y con algo dignamente lo que pasó aquí. Si no esta tierra no se puede consagrar” (entrevista, septiembre del 2016).

Un cadáver humano, sin importar quién fue en vida, no merece abandono. Exhumar los cuerpos permitirá al lugar sanar, a los familiares de estos desaparecidos elaborar su duelo y a los espíritus lograr su transición al más allá. La posibilidad de sanar el territorio de esta manera halla fundamento en la experiencia que algunos mayores han tenido con los encantos que se encuentran en la selva. Encantos son los espíritus y los tesoros antiguos enterrados en la región así como los entierros de los indios y las ofrendas de oro con que eran acompañados. También lo son las morrocotas escondidas en la selva por los españoles durante la Colonia. La mayor parte de estos tesoros son protegidos por un espíritu guardián. Según algunos relatos, en muchos casos ese espíritu pertenecía a algún esclavo asesinado por su amo en el lugar del entierro para que su alma se quedara allí protegiendo el oro. Lo que saben los mayores es que, cuando estos tesoros son removidos, los espíritus que los protegían se liberan de su obligación y dejan de morar en el lugar. De la misma forma, se presume que hasta tanto los cuerpos de quienes murieron en Caño Claro no sean desenterrados, sus espíritus van a continuar habitando allí y causando dificultades a los vivos: "Entonces, al moverlos de un sitio para otro sitio”, me explicó Pontus, “al quitarlos de ahí, pensamos y creemos que todo puede tener una mejoría. Además, si lo hace el Estado colombiano se va a quitar un poco esas visiones de que aquí es donde permanece la guerrilla”.

Los muertos, sin duda, merecen mejor destino que convertirse en alimento de aves carroñeras. De ahí la propuesta de exhumación. Lo que lleva a las comunidades de Caño Claro a solicitar que sea el Estado quien remueva estos cuerpos es el deseo de cambiar el estigma sobre la influencia guerrillera en la zona, pero también que dicha exhumación adquiera ciertos tintes reparativos. Así, la identificación de esos cadáveres ayudará a las comunidades locales a reparar su propio territorio, pues sus lugares de trabajo dejarán de estar habitados por estas presencias. Pero hay algo más en la propuesta planteada. Ovidio menciona 
que hay que reconocer pública y dignamente lo que pasó en ese lugar. La palabra dignidad resulta importante: desenterrar decenas de cuerpos que se encuentran abandonados en la selva y develar sus identidades ayudará tanto a los vivos como a los muertos a recobrar parte de la dignidad perdida. Para los habitantes de Caño Claro, una exhumación oficial arrojará claridad sobre los hechos y demostrará que ellos no tuvieron nada que ver con los asuntos de la guerrilla. La dignidad de estos espíritus y de sus familiares también está en juego: los muertos serán finalmente identificados y sepultados, y sus familiares encontrarán alivio al drama de la desaparición de sus seres queridos.

Quizá lo que encuentro más importante en la propuesta de la gente de Caño Claro es el explícito reconocimiento de la dignidad que merecen estos insepultos combatientes. A pesar de que Ovidio mismo ha sido objetivo de ataques y amenazas por parte de los paramilitares, aun cuando Pontus es un líder social amenazado que debe moverse bajo la protección de un esquema de seguridad brindado por el Estado, y a pesar de que las familias de Caño Claro han sido todas víctimas directas de las acciones criminales de los paramilitares, todos reconocen que estos combatientes deben estar siendo buscados y llorados por sus respectivas familias. Sin importar el daño que causaron en vida, estos muertos merecen ser tratados con cierto decoro. Las siguientes palabras de Ovidio me ayudaron a entender que estas víctimas de la violencia paramilitar no ven necesariamente a sus victimarios como monstruos absolutos:

La lucha es de pobre con pobre [...] No hay un hijo de rico en el ejército, no hay un hijo de rico en la guerrilla, no hay un hijo de rico en el paramilitarismo. Son los hijos de nosotros [los campesinos] los que están ahí. A nosotros nos desplazan y después que nos desplazan, se surten de nosotros, se surten de nuestros hijos que están sufriendo. Ese es el peso de conciencia que está ahí en la boca de Caño Claro. ¿Cuántas madres están buscando a esos muertos? ¿Cien madres? ¿Ochenta madres? No sabemos, pero hay muchas madres que están esperanzadas. (Entrevista, septiembre del 2016)

Estas palabras fueron un regalo precioso. Ovidio usa la expresión peso de conciencia para describir aquello que mora en Caño Claro. Este peso de conciencia no debe confundirse con remordimiento; después de todo, las comunidades locales no sienten tal cosa por lo sucedido a quienes los desplazaron de sus tierras. Tampoco se trata de que estén juzgando moralmente a la guerrilla por haber realizado el ataque. El peso de conciencia es una carga, un agobio situado en el lugar mismo. Es la forma en que Ovidio describe el conjunto de impresiones sensoriales que habitan el lugar, los afectos (Thrift 2008), "los trazos de energía” (Stewart 2007, 70), “las fuerzas e intensidades” (Seigworth y Gregg 2010, 2) o "los 
sentimientos exudados” (Navaro-Yashin 2009, 11) por los eventos acaecidos allí. Dice algo sobre el estado de indefensión y vulnerabilidad que experimentan los habitantes locales, los muchos intereses que siguen cernidos sobre sus territorios colectivos, el abandono del Estado, el poder de una élite económica que logró transformar tierras de producción campesina en megacultivos de palma de aceite, el estado de terror impuesto por grupos armados. Y, sin embargo, peso de conciencia expresa una esencia, algo que se sitúa en la interfase de los mundos humanos y el lugar mismo. En este sentido, el peso de conciencia es una atmósfera que flota en el ambiente, una fuerza que habita el lugar y que no proviene solamente de ciertas impresiones subjetivas. En suma, es un tipo de afecto a través del cual el lugar mismo se hace sentir (Hastrup 2010, 194).

Lo que emana de Caño Claro es un tipo de sufrimiento e injusticia: la injusticia de los múltiples crímenes cometidos contra las comunidades locales por quienes construyeron su campamento allí; la injusticia contra el territorio mismo que fue violentamente ocupado y usado para fines muy distintos a los que las comunidades tradicionalmente le dan; el sufrimiento de las familias desterradas; pero también el sufrimiento de los muertos cuyos cuerpos fueron dejados a la buena de la selva. Esta es la razón por la que la propuesta de Ovidio - exhumar los cuerpos de sus victimarios para que sus respectivas familias puedan despedirlos- es ecuménica: enlaza a través de una misma acción a la gente, a los espíritus y a los lugares que han sufrido violencia; interpela al Estado, a las comunidades locales y a los familiares que buscan a sus muertos. Resulta, sin embargo, importante aclarar que esta propuesta ecuménica no se deriva de un sentimiento de compasión de las familias locales hacia los paramilitares. No es tanto que Ovidio, Pontus o doña Aleyda sientan pesar por lo sucedido a estos combatientes. Su empatía se dirige más bien a los familiares de estos soldados: madres y padres campesinos que, como ellos, tienen familiares desaparecidos y continúan sufriendo por no saber la suerte de sus hijos. "¿Cuántas madres están buscando a esos muertos?”, se preguntaba Ovidio. Se trata entonces de un profundo sentimiento de empatía con el dolor cargado por los familiares de estos soldados, una experiencia que en el fondo es similar a la que ellos también han experimentado como víctimas.

Remover el peso de conciencia que habita en Caño Claro y que impide que las familias que retornaron puedan vivir tranquilas es el objetivo final de la propuesta de exhumación e identificación de los cadáveres. Es, como describía Pontus, un acto de dignidad hacia los vivos, hacia los muertos y hacia el territorio mismo. En un escenario de paz, justicia y reconciliación, esta es una propuesta de la que se beneficiarán humanos, no humanos y lugares. El acto de dignidad 
propuesto no es necesariamente de lamento por los combatientes asesinados, sino más bien un acto para aliviar el dolor de los familiares que los están buscando, para permitir que los espíritus continúen su camino al más allá, para sanar al territorio y que las actividades tradicionales de las familias que retornaron tengan lugar de nuevo. Como puede apreciarse, al invocar al Estado como actor fundamental de este acto de dignidad, las comunidades locales no están simplemente llamando la atención sobre el bienestar al que tienen derecho los humanos, sino que abren la esfera de acción pública a los espíritus y al territorio. Lugares y espíritus, tanto como las personas, se tornan en sujetos de cuidado y atención puesto que los efectos de la guerra trascienden el marco de los derechos de los humanos. Las comunidades de Caño Claro buscan tanto reparar sus propias relaciones con el territorio, como que los espíritus restablezcan sus relaciones con los vivos y puedan continuar su tránsito al más allá. En juego está, entonces, aliviar el sufrimiento del territorio, aliviar las dificultades que pasan las comunidades que retornaron a sus tierras, y sanar el dolor de los espíritus y de sus familiares. En este sentido, el acto de dignidad por el que abogan las comunidades locales busca revertir la incompletitud, brusquedad y falta de clausura asociados con los efectos que la muerte violenta produce tanto en los vivos como en los muertos.

\section{Conclusión}

En este texto he descrito algunas de las relaciones que las comunidades de Caño Claro cultivan con los territorios a los que retornaron luego de su desplazamiento forzado. Aun cuando ya no hay presencia física de los grupos armados involucrados (las Autodefensas Unidas de Colombia [AUC] se desmovilizaron en el 2006 y las FARC en el 2016), algunos sitios continúan permeados por los efectos de sus violencias, particularmente por una serie de seres fantasmales que comprometen las posibilidades de que tanto las familias que retornaron como sus territorios colectivos logren sanar. Toda vez que estos muertos continúan impidiendo que las comunidades retornantes puedan retomar sus proyectos de vida, la presencia de los espíritus de quienes sufrieron una mala muerte puede entenderse como otro tipo de violencia: una violencia lenta (Nixon 2011, 2), de repercusiones pospuestas y destrucción diferida que, aunque menos espectacular que la violencia armada, amenaza el bienestar de los vivos, de los muertos y de sus respectivos mundos. A fin de reconstruir los proyectos de vida familiares y comunitarios, 
recuperar la base económica, sanar las heridas de la guerra y lograr que el territorio recobre sus cualidades materiales y anímicas, las relaciones con estos espíritus no son una opción sino una condición. Para las comunidades de Caño Claro es menester entonces cultivar adecuadas relaciones con estos espíritus, ya que solo de esta manera el territorio será nuevamente habitable y podrán los vivos y los muertos alcanzar aquello que denominé una paz ecuménica.

He querido destacar también los dilemas que enfrentan estas comunidades en el momento de confrontar a tales espíritus. Ellas no son solo vestigios de una violencia pasada pues hasta el día de hoy otros grupos armados continúan haciendo presencia y ejerciendo control social y económico en la región, particularmente los neoparamilitares que han acogido el eufemístico nombre de Autodefensas Gaitanistas de Colombia y la guerrilla del Ejército de Liberación Nacional (ELN). Así, más que la superación de una violencia que no ha cesado o la reconciliación con un pasado doloroso, lo que ponen de manifiesto estos seres fantasmales es la posibilidad de sanar el territorio y, con ello, lograr un objetivo más ambicioso: establecer las condiciones para que los espíritus que se derivan de una mala muerte puedan partir en paz. Este fin, inspirado parcialmente en una cultura de misericordia hacia los muertos, encuentra su razón de ser en una consideración ética hacia los vivos, en este caso, hacia los familiares de los combatientes que deben estar buscando a sus desaparecidos. Esta compasión se deriva de las experiencias de dolor y sufrimiento por las que muchas familias del Bajo Atrato han tenido que atravesar: varias aún están en búsqueda de sus familiares desaparecidos; otras perdieron a sus seres queridos sin tener la oportunidad de prodigarles sepulturas adecuadas. En última instancia, las lealtades políticas de estos combatientes no son tan importantes como el sufrimiento que sus familiares y las comunidades locales comparten.

De alguna forma, la presencia de estos espíritus representa un fracaso colectivo: el fracaso militar de quienes murieron en combate; el de las comunidades locales que no tienen los medios, y en algunos casos el deseo, de hacerse cargo de estos cuerpos insepultos; el de las familias de estos combatientes desaparecidos, que carecen de los recursos y de la información para dar con el paradero de sus seres queridos; el del Estado, que ha tenido poca o ninguna voluntad para responder a la solicitud de exhumación que las comunidades locales han presentado; y quizá el fracaso de la sociedad colombiana en general, puesto que, como lo insinuaba Ovidio, ha facilitado un sistema injusto en el que jóvenes de clases desfavorecidas han terminado por librar una guerra que no ha hecho sino facilitar los intereses de una poderosa élite económica y política. Este fracaso colectivo es lo que corroe aquel lugar a las orillas de Caño Claro y lo que dificulta la sanación de las comunidades y sus territorios. 
Facilitar las condiciones para que quienes sufrieron una mala muerte puedan descansar: esta es una preocupación más bien ontológica, pues lo que está en juego es el bienestar de diferentes tipos de seres. La ausencia de un adecuado lugar donde sus restos mortales puedan morar es lo que, en últimas, ha condenado a estos espíritus a deambular por el sitio en el que murieron. Mientras continúen habitando allí, no habrá posibilidad de que las comunidades y sus territorios puedan sanar. Han de entenderse entonces los esfuerzos de las comunidades de Caño Claro por retornar a sus tierras, reconstruir sus casas y recuperar sus cultivos de pancoger, y también por insertar a estos espíritus dentro del adecuado flujo del tiempo y del ser como un acto eminentemente político: ambos persiguen restablecer relaciones entre distintos tipos de seres (humanos, cultivos, animales, espíritus), ambos apuntan a una ocupación armónica de lugares existenciales, ambos buscan sanar el territorio colectivo de los perversos efectos de la violencia armada. Y es esta intención de dispensar cuidados a diferentes clases de seres y favorecer el entrelazamiento de los mundos humanos y no humanos lo que constituye una acción ecuménica que torna un territorio violentado en uno habitable.

\section{Referencias}

Berque, Augustin. 1987. Écoumène. Introduction à l'étude des milieux humaines. París: Belin.

Casey, Edward. 1996. "How to Get from Space to Place in a Fairly Short Stretch of Time”. En Senses of Place, editado por Steven Feld y Keith H. Basso, 13-52. Santa Fe: School of American Research Press.

CIJP (Comisión Intereclesial de Justicia y Paz). 2005. La Tramoya: derechos humanos y palma aceitera, Curvaradó y Jiguamiandó. Bogotá: Cinep y CIJP.

Das, Veena. 1997. "Language and Body: Transactions in the Construction of Pain”. En Social Suffering, editado por Veena Das, Arthur Kleinman y Margaret Lock, 67-91. Berkeley: University of California Press.

—. 1998. "Wittgenstein and Anthropology". Annual Review of Anthropology 27: 171-195.

Eliade, Mircea. 1971. The Myth of the Eternal Return: Cosmos and History. Princeton: Princeton University Press.

Escobar, Arturo. 2008. Territories of Difference. Place, Movements, Life, Redes. Durham; Londres: Duke University Press.

Friedemann, Nina S. de. 1974. “Minería del oro y descendencia: Güelmambí, Nariño”. Revista Colombiana de Antropología 16: 9-52. 
Hastrup, Kristen. 2010. "Emotional Topographies: The Sense of Place in the Far North". En Emotions in the Field: The Psychology and Anthropology of Fieldwork Experience, editado por James Davies y Dimitrina Spencer, 191-211. Stanford: Stanford University Press.

Hertz, Robert. (1909) 1960. A Contribution to the Study of the Collective Representation of Death. Glencoe: The Free Press.

Jimeno, Myriam. 2004. Crimen pasional. Contribución a una antropología de las emociones. Bogotá: Universidad Nacional de Colombia.

—. 2007. "Lenguaje, subjetividad y experiencias de violencia”. Antípoda 5: 169-190.

Kwon, Heonik. 2008. Ghosts of War in Vietnam. Cambridge: Cambridge University Press.

Lara, Alí y Giazú Enciso Domínguez. 2013. “El giro afectivo”. Athenea Digital 13 (3): 101-119.

Losonczy, Anne-Marie. 2006. La trama interétnica. Ritual, sociedad y figuras de intercambio entre los grupos negros y emberá del Chocó. Bogotá: Instituto Colombiano de Antropología e Historia; Instituto Francés de Estudios Andinos.

Lutz, Catherine y Geoffrey White. 1986. “The Anthropology of Emotions”. Annual Review of Anthropology 15: 405-436.

Massumi, Brian. 2002. Parables for the Virtual: Movement, Affect, Sensation. Durham: Duke University Press.

Merleau-Ponty, Maurice. (1945) 2002. Phenomenology of Perception. Londres; Nueva York: Routledge.

Navaro-Yashin, Yael. 2009. "Affective Spaces, Melancholic Objects: Ruination and the Production of Anthropological Knowledge”. Journal of the Royal Anthropological Institute 15: 1-18.

-. 2012. The Make-Believe Space: Affective Geography in a Postwar Polity. Durham: Duke University Press.

Nieto, Patricia. 2012. Los escogidos. Medellín: Alcaldía de Medellín; Sílaba Editores.

Nixon, Rob. 2011. Slow Violence and the Environmentalism of the Poor. Cambridge: Harvard University Press.

Observatorio del Programa Presidencial de Derechos Humanos. 2003. Panorama actual del Chocó. Bogotá: Presidencia de la República, Ministerio del Interior.

Oslender, Ulrich. 2004. "Fleshing Out the Geographies of Social Movements: Colombia's Pacific Coast Black Communities and the 'Aquatic Space’”. Political Geography 23: 957-985.

-. 2008. Comunidades negras y espacio en el Pacífico colombiano. Hacia un giro geográfico en el estudio de los movimientos sociales. Bogotá: Instituto Colombiano de Antropología e Historia; Universidad Colegio Mayor de Cundinamarca; Universidad del Cauca.

Pelkmans, Mathijs. 2013. “The Affect Effect”. Anthropology of this Century 7. http://aotcpress. com/articles/affect-effect/

Perera, Sasanka. 2001. "Spirit Possessions and Avenging Ghosts. Stories of Supernatural Activity as Narratives of Terror and Mechanisms of Coping and Remembering”. En Remaking 
a World. Violence, Suffering and Recovery, editado por Arthur Kleinman, Veena Das, Margaret Lock, Mamphela Ramphela y Pamela Reynolds, 157-200. Berkeley: University of California Press.

Quiceno, Natalia. 2015. "Vivir sabroso: poéticas de la lucha y el movimiento afroatrateño en Bojayá, Chocó (Colombia)”. Tesis doctoral, Departamento de Antropología Social, Museo Nacional, Universidad Federal do Rio de Janeiro, Río de Janeiro.

Seigworth, Gregory y Melissa Gregg. 2010. "An Inventory of Shimmers”. En The Affect Theory Reader, editado por Melissa Greg y Gregory Seigworth, 1-25. Durham; Londres: Duke University Press.

Serrano, José. 1994. "Cuando canta el guaco: la muerte y el morir en poblaciones afrocolombianas del río Baudó, Chocó”. Tesis de grado, Departamento de Antropología, Universidad Nacional de Colombia, Bogotá.

Seyfert, Robert. 2012. "Beyond Personal Feelings and Collective Emotions: Toward a Theory of Social Affect”. Theory, Culture \& Society 29 (6): 27-46.

Spinoza, Benedictus de. (1677) 2001. Ethics. Traducido por W. H. White y A. H. Stirling. Londres: Wordsworth.

Stewart, Kathleen. 2007. Ordinary Affects. Durham; Londres: Duke University Press.

Taussig, Michael. 1992. The Nervous System. Nueva York; Londres: Routledge.

Thrift, Nigel. 2008. Non-Representational Theory: Space, Politics, Affect. Nueva York: Routledge.

Trujillo Molano, Jimena. 2012. “Escribir sobre lo intangible. Vivir lo sagrado”. En Etnografías contemporáneas. Trabajo de campo, editado por Sandra Murillo, Myriam Jimeno y Marco Martínez, 181-208. Bogotá: Universidad Nacional de Colombia.

Valencia, Armando. 2013. "Alternativas organizativas ante la guerra y el desplazamiento en el bajo Atrato”. Revista de Estudios del Pacífico Colombiano 1: 57-81.

Velásquez, Rogerio. (1961) 2000. "Ritos de la muerte en el Alto y Bajo Chocó”. En Fragmentos de historia, etnografía y narraciones del Pacífico colombiano negro. Bogotá: Instituto Colombiano de Antropología e Historia.

Whitten, Norman. 1974. Black Frontiersmen. A South American Case. Nueva York: Schenkman Publising Company.

\section{Filmografía}

Del Toro, Guillermo, dir. 2001. El espinazo del diablo. México; España: Canal+ España; Good Machine; Sogepaq; Sony Pictures Classics.

Echavarría, Juan Manuel. 2013. Requiem NN. 2013. Colombia: Lulo Films. 